
\title{
25 Research Soure \\ Early Gene Expression Response of Barley Root Tip to Toxic Concentrations of Cadmium
}

\section{Lubica Liptáková}

Slovak Academy of Sciences: Slovenska akademia vied

\section{Loriana Demecsová}

Slovak Academy of Sciences: Slovenska akademia vied

Katarína Valentovičová

Slovak Academy of Sciences: Slovenska akademia vied

Veronika Zelinová

Slovak Academy of Sciences: Slovenska akademia vied

\section{Ladislav Tamás ( $\nabla$ ladislav.tamas@savba.sk)}

Slovak Academy of Sciences: Slovenska akademia vied https://orcid.org/0000-0002-9284-4483

\section{Research Article}

Keywords: antimycin A, indole-3-acetic acid, oxidative stress, 4-phenoxyphenylboronic acid (PPBo), rotenone, defense responses

Posted Date: August 5th, 2021

DOI: https://doi.org/10.21203/rs.3.rs-761487/v1

License: (c) (i) This work is licensed under a Creative Commons Attribution 4.0 International License. Read Full License

Version of Record: A version of this preprint was published at Plant Molecular Biology on December 20th, 2021. See the published version at https://doi.org/10.1007/s11103-021-01233-w. 


\section{Abstract}

Even a short, $30 \mathrm{~min}, \mathrm{Cd}$ treatment of roots induced a considerable alteration in gene expression in the barley root tips within an hour after the treatments. The very early activation of MYB1 transcription factor expression is partially regulated by auxin signaling in mildly stressed seedlings. An increase in allene oxide cyclase and NADPH oxidase expression was a distinguishing feature of root tips response to mild $\mathrm{Cd}$ stress and their expression is activated via IAA signaling. Meanwhile, early changes in the level of dehydrin transcripts were detected in moderately and severely stressed root tips, and their induction is related to altered ROS homeostasis in cells. The early activation of glutathione peroxidase expression by mild Cd stress indicates the involvement of IAA in the signaling process. In contrast, early APX expression was induced only with $\mathrm{Cd}$ treatment causing severe stress and ROS play central roles in its induction. The expression of cysteine protease was activated similarly in both mildly and severely Cd-stressed roots; consequently, both increased IAA and ROS levels take part in the regulation of C-Prot expression. The Cdevoked accumulation of BAX Inhibitor-1 mRNA was characteristic for moderately and severely stressed roots. Whereas decreased IAA level did not affect its expression, rotenone-mediated ROS depletion markedly reduced the Cd-induced expression of BAX Inhibitor-1. An early increase of alternative oxidase levels in the root tip cells indicated that the reduction of mitochondrial superoxide generation is an important component of barley root response to severe Cd stress.

\section{Introduction}

Cadmium (Cd) is an undesirable environmental pollutant without any known function in higher plants. Nevertheless, some plant species, so-called hyperaccumulators, tolerate high concentrations of heavy metals, including $\mathrm{Cd}$, in the surroundings and even accumulate them in their tissues; therefore, they are effectively used in phytoremediation processes to decontaminate soils with high concentrations of toxic metals (Rascio and Navari-Izzo, 2011). On the other hand, it is necessary to maintain the level of toxic metals in crops as low as possible, as the consumption of contaminated food endangers human health (Clemens, 2019; Pan et al., 2010). In addition, most of the agriculturally important plants are very sensitive even to low concentrations of $\mathrm{Cd}$ in the soil, which negatively affects crop yield. A variety of anthropogenic activities, particularly mining industry, transport, landfills as well as the use of pesticides and fertilizers in agriculture, are the main contributors to soil Cd contamination (Pan et al., 2010).

A number of symptoms demonstrate the negative $\mathrm{Cd}$ effect on plant development and growth. The very early and most typical plant response to $\mathrm{Cd}$, as to other metal excess-induced stress, is rapid inhibition of root growth (RGI). For a long time, RGI has exclusively been considered a toxicity symptom of metal stress; however, recently, it became widely regarded as a part of mainly auxin-mediated root growth reorientation during different abiotic stress-induced adaptations (Kazan, 2013; Potters et al., 2009). Besides this rapid $\mathrm{RGI}$, due to the reduced cell elongation and cell division, root thickening, twisting, enhanced root hair formation and root branching are the main characteristic features of toxic metal excess-induced changes in root system architecture and morphology. The changes are probably associated with the evasion of roots from the source of stresses, such as high concentrations of toxic 
metals, to avoid irreversible damages of root tissues (Bochicchio et al., 2015). Moreover, a considerable amount of evidence shows that alteration in phytohormones metabolism and signaling is a part of the stress-induced metabolic defense responses (Zulfiqar and Ashraf 2021). An altered level of the most abundant auxin, the indole-3-acetic acid (IAA), has been described in various plant roots that were exposed to Cd (Han et al., 2020; Hu et al., 2013; Ronzan et al., 2019). A recent report showed that mild Cd stress increases the IAA synthesis and accumulation, whereas it is rapidly decreased during severe stress in the root tips of barley (Demecsová et al., 2020). Jasmonic acid (JA) is another ubiquitous plant signaling compound, which functions in both root morphogenic and defense responses to various stresses, including metal stress (Wang et al., 2020a). In addition, JA signaling was also linked to the regulation of metal uptake, accumulation and detoxification (Lei et al., 2020; Chen et al., 2021). During both biotic and abiotic stress, a key role is played by allene oxide cyclase (AOC), an important enzyme in the JA biosynthesis pathway (Sun et al., 2020). In response to a diverse abiotic stress, as well as in the regulation of basic developmental and metabolic processes, MYB transcription factors (TF) represent one of the largest TF families in plants (Li et al., 2015). In Arabidopsis, MYB TFs participated in the regulation of $\mathrm{Cd}$ uptake and accumulation, in the activation of antioxidant defense response and Cd detoxification mechanisms (Zhang et al., 2019; Agarwal et al., 2020).

With increasing concentration of $\mathrm{Cd}$ in the cultivation medium and increasing exposure time, the $\mathrm{Cd}$ uptake and accumulation is enhanced in root tissues (Wang et al., 2007), strongly affecting a number of biochemical and physiological processes in cells (Gallego et al., 2012). Although Cd is not a redox-active metal, its main mechanism of toxicity is the induction of oxidative stress (Sharma and Dietz, 2008). This is due to the disruption of the equilibrium between the generation and detoxification of reactive oxygen species (ROS). ROS, depending on their concentration, have a dual function in stress responses: participating either in cell signaling or damage (Romero-Puertas et al., 2019). At the low concentration, generated under moderately adverse conditions, ROS are important signaling molecules responsible for activating the defense response and acclimation. Increasing evidence shows that the plasma membrane NADPH oxidases (NOX), responsible for apoplastic superoxide formation in plant tissues, are key players in phytohormone signaling both in the development and stress responses of plants (Sun et al., 2019). During Cd stress, increased activity of NOX has been described in various plant species, and it is more likely involved in different defense responses rather than in an uncontrolled toxic superoxide generation (Jakubowska et al., 2015; Tamás et al., 2016). In turn, numerous publications have indicated that the sites of increased toxic ROS formation in roots exposed to different metals are mitochondria (Keunen et al., 2011; Tamás et al., 2016). This observation is also supported by the fact that the activation of alternative oxidase (AOX), which markedly reduces the ROS production in mitochondria, is a general response of plant cells not only to metal but to other stress conditions as well (Vanlerberghe, 2013). In a highly Cd-tolerant Euglena, the main component of Cd toxicity resistance is the enhanced alternative respiration (Castro-Guerrero et al., 2008). Since irreversible cell damage or cell death can be elicited by intensive ROS accumulation, the activation of the antioxidant system, already at the early stages of oxidative stress, is inevitable for the protection of cells from oxidative damage (Kapoor, 2019). Heavy metals, including Cd, activated several important components of the antioxidant systems, both enzymatic 
and non-enzymatic, in various subcellular compartments; however, ascorbic acid and glutathione with their related enzymes, among them mainly ascorbate peroxidase (APX) and glutathione peroxidase (GPX), represent a key part in plants for metal excess-induced ROS detoxification (Anjum et al., 2012; 2014).

In the protection, stabilization and repair of biomolecules, mainly under stress conditions, an important role is played by dehydrins ( $\mathrm{DHN}$ ), multifunctional proteins binding to membranes, nucleic acids and proteins (Yu et al., 2018). In addition to their ability to bind macromolecules, some DHNs are able to bind small ligands, including metal ions, thereby markedly reduced the metal-induced toxic symptoms, such as the formation of ROS in cells (Hara et al., 2013). On the other hand, the rapid recycling of unamendable proteins is also crucial under stress conditions. The removal of abnormal/damaged proteins is one among the several other functions of plant proteases, as a part of the quality control of proteins in cells (Palma et al., 2002). Previous reports in pea seedlings showed that $\mathrm{Cd}$ evokes a marked oxidative modification of proteins accompanied by enhanced proteolytic activity (Romero-Puertas et al., 2002). In plant, multifunctional cysteine proteases (C-Prot) takes part in plant growth and development, storage protein mobilization, senescence, cell death and also in response to both biotic and abiotic stresses (Grudkowska and Zagdańska, 2004). Under the more severe stress conditions, ROS production is further increased, exceeding the capacity of antioxidant systems of cells to effectively capture them, resulting in oxidative damage of important biomolecules. The increased amount of misfolded or unfolded proteins during oxidative stress can activate mechanisms of both repair and elimination; nevertheless, under severe stress, the high amount of damaged proteins may evoke the activation of cell death (Depaepe et al., 2021). A conserved endoplasmic reticulum-localized suppressor of cell death, BAX Inhibitor-1 (BAXI-1), regulates the threshold of cell death activation in the cell response to various stresses (Watanabe and Lam, 2009; Ishikawa et al., 2011). An elevated level of BAXI-1 was observed in response to different abiotic stresses; including those induced by heavy metal excess (Isbat et al., 2009).

In the present work, we looked into the barley root tip early gene expression responses to $\mathrm{Cd}$ during a short-term treatment of roots with different $\mathrm{Cd}$ concentrations. This $\mathrm{Cd}$-induced response was compared with the alteration in gene expression induced by IAA, as an important signaling molecule under mild and moderate Cd stress, and Antimycin A (AA), as an activator of mitochondrial ROS formation, which is one of the main symptoms of severe $\mathrm{Cd}$ stress toxicity. In addition, 4-phenoxyphenylboronic acid (PPBo), an inhibitor of IAA synthesis, and rotenone, an inhibitor of mitochondrial complex I, were used to reduce IAA level and superoxide generation at mitochondrial complex III, respectively.

\section{Materials And Methods}

\subsection{Plant material, growth conditions and treatments}

The plant material was grown according to Demecsová et al. (2020). Briefly, uniformly germinating seeds of barley (Hordeum vulgare L.), cv. Slaven (from Slovakia, Sládkovičovo-Nový Dvor, Plant Breeding Station, Hordeum Ltd), were arranged into rows between two sheets of distilled water ( $\mathrm{dw}$ )-moistened 
filter paper in rectangle and incubated in a nearly vertical position. The filter papers in rectangle dishes were kept moist from a reservoir of dw using a wick of filter paper. Seedlings $60-65 \mathrm{~h}$ after the onset of imbibition, with roots approximately $4-5 \mathrm{~cm}$ long, were used for treatments. The short-term treatments took 30 min, during which the seedlings roots were immersed in different solutions: in dw (for control); into 10,30 or $60 \mu \mathrm{M} \mathrm{CdCl}_{2}$ with or without $5 \mu \mathrm{M}$ rotenone; or into $2.5,5$ or $10 \mu \mathrm{M}$ IAA; or into 5,10 or 20 $\mu \mathrm{M}$ AA. Following these treatments, the roots were for 5 min rinsed in $\mathrm{dw}$, after which they were placed on trays between two sheets of filter paper moistened in dw or $50 \mu \mathrm{M}$ PPBo and $0.1 \%$ DMSO (from $50 \mathrm{mM}$ stock in DMSO) and incubated for 1, 2, 3 or $6 \mathrm{~h}$.

\subsection{Analysis of root morphology and length increment}

The increment of root length was determined $6 \mathrm{~h}$ after the transient treatments, as described in Demecsová et al., (2020). At the beginning of the incubation time (following the short-term treatments), the position of the longest root tip for each seedling was marked on the filter paper. Following the $6 \mathrm{~h}$ incubation, the root tips were excised at the marked place on the filter paper, and the increment in root length was measured by an image analyzer.

\subsection{Western blot analysis}

Protein extract was prepared from the root tips (fifty root tips, $3 \mathrm{~mm}$ in length, of the two longest roots of seedlings) by homogenization in a cold $100 \mathrm{mM}$ Tris-HCl buffer (pH 8.0) with $1 \mathrm{mM}$ EDTA and $5 \%$ glycerol. After centrifugation at $12000 \mathrm{xg}$ for $10 \mathrm{~min}$, the resulting pellet, containing also mitochondria, was resuspended in the RIPA buffer ( $50 \mathrm{mM}$ Tris-HCl buffer; $\mathrm{pH}$ 8.0, containing $1 \mathrm{mM}$ EDTA, $1 \%$ TritonX$100,0.5 \%$ Na-deoxycholate, $0.1 \%$ SDS and $5 \%$ glycerol) and homogenized with a microtube homogenizer at $40^{\circ} \mathrm{C}$. Following centrifugation at $12000 \mathrm{xg}$ for $10 \mathrm{~min}$, the amount of proteins in the supernatant was quantified with bovine serum albumin as the calibration standard by the method of Bradford (1976). After SDS-PAGE and blotting to a nitrocellulose membrane, the immunodetection was carried out using antibodies against plant AOX1/2 (Agrisera) and the Amplified Opti-4CN detection kit (Bio-Rad).

\subsection{Semi-quantitative RT-PCR analysis}

Fifty root tips ( $3 \mathrm{~mm}$ in length) of the two longest roots of seedlings were used for the isolation of total RNA. The isolation was done using the ISOLATE II RNA Plant Kit (Bioline). Using anchored oligo $(\mathrm{dT})_{23}$ primers and $2 \mu \mathrm{g}$ of DNase-treated total RNA, the cDNA was synthesized with Tetro cDNA Synthesis Kit (Bioline). Gene-specific primers were prepared in accordance with the published sequences (Suppl. 1). As an internal positive control, actin and ubiquitin expression were used. After amplification reaction (using MyTAq $^{\text {TM }}$ HS Red Mix - Bioline) the PCR products were applied to agarose gel and stained with GelGreen (Biotium).

\section{Results And Discussion}


It has previously been shown (Demecsová et al., 2020) that in the barley root tips, mild Cd stress ( $10 \mu \mathrm{M}$ Cd for $30 \mathrm{~min}$ ) evokes increased IAA synthesis and accumulation, and this change in IAA level is partially responsible for both morphogenic and defense responses. Meanwhile, severe (60 $\mu \mathrm{M} \mathrm{Cd}$ for $30 \mathrm{~min}) \mathrm{Cd}$ stress induces a rapid decrease of IAA level. During moderate $\mathrm{Cd}$-stress ( $30 \mu \mathrm{M} \mathrm{Cd}$ for $30 \mathrm{~min}$ ), there is a transient depletion of IAA in the root tips, and then its level increases compared to the untreated seedlings, in a similar fashion as observed during mild Cd stress. The involvement of IAA in Cd-induced response was supported also by the observation that $\mathrm{Cd}$ up-regulated the tryptophan synthase gene transcription, resulting in an elevated tryptophan content, the main precursor of IAA, in Arabidopsis seedlings (Sanjaya et al., 2008). Moreover, the authors also observed that exogenously applied tryptophan or the overexpression of the tryptophan synthase gene provide enhanced $\mathrm{Cd}$ tolerance, which suggests the possible involvement of tryptophan in the plant defense response to $\mathrm{Cd}$. Additionally, direct IAA level modulation in plant tissue has a considerable effect on drought stress (Shi et al., 2014). While mutants in genes involved in IAA synthesis (with lower IAA level) showed increased sensitivity, transgenic lines with higher endogenous IAA content exhibited enhanced tolerance to water deficit. Besides the depletion of IAA level observed in moderately and severely stressed seedlings, Cd also induced superoxide generation as a very early symptom of stress in the root tips (Tamás et al., 2016). It has recently been suggested that this Cd-mediated superoxide generation, similarly to AA-mediated superoxide accumulation, is originated from the mitochondrial complex III (Zelinová et al., 2019). Based on the results in these experiments, we compared the Cd-, IAA- and AA-induced alteration in gene expression in barley root tips. The concentrations of IAA and AA were chosen so that all short-term treatments, already at the lowest used concentration, evoked a considerable but similar inhibition of primary root growth, which further increased with increasing concentrations of Cd, IAA or AA (Fig. 1).

It is a widely accepted fact that AOX has a key role in reducing the superoxide generation in plant mitochondria. Antisense suppression of AOX caused a buildup of ROS in cells, whereas the cells where AOX was overexpressed had lower ROS formation (Maxwell et al., 1999). In our experiments, western blot analysis revealed that the AOX protein levels increase in a Cd concentration-dependent manner $3 \mathrm{~h}$ after the short-term Cd treatment (Fig. 2). This early increase of AOX levels in root tip cells indicates that the reduction of ROS generation by inhibition of mitochondrial complex III and IV activity is an important component of barley root response to Cd stress. In a highly Cd-tolerant Euglena, enhanced alternative respiration accounted for $69 \%$ of total respiration in the presence of Cd (Castro-Guerrero et al., 2008). On the contrary to $\mathrm{Cd}$ treatment, a $2.5 \mu \mathrm{M}$ concentration of IAA had no effect on the AOX protein levels, although this concentration evoked a marked inhibition of root growth. However, in roots that were exposed to higher IAA concentrations considerable higher AOX levels were observed than in control root tips (Fig. 2). In turn, a marked increase in AOX protein abundance was observed already at $5 \mu \mathrm{M} \mathrm{AA}$ treatment, and only a slight additional increase was detected at higher AA concentrations. An antagonistic relationship between IAA and mitochondrial ROS generation has been described in Arabidopsis, where AA treatment caused an inhibition of auxin signaling, and vice versa, auxin diminished the AA-induced response, including AOX expression (Ivanova et al., 2014; Kerchev et al., 2014). Therefore, the detected increase in AOX protein levels after the transient treatment of roots with 
high IAA concentrations is probably a consequence of an IAA-induced response, such as ROS generation or ABA synthesis, but not a direct activation of AOX by IAA. Increased IAA level in the roots of Cd-exposed tall fescue seedlings was accompanied by elevated $\mathrm{H}_{2} \mathrm{O}_{2}$ content and increased antioxidant enzyme activities (Han et al., 2020). It is supported also by the observation that the reduction of IAA synthesis by PPBo did not affect the AOX protein levels either in control or in Cd-treated roots (Fig. 3). Previous research carried out with Arabidopsis implied that the inhibition of complex I in mitochondria by rotenone did not induce an expected oxidative stress or cell death, but rather numerous metabolic pathways were redirected, including activation of AOX (Garmier et al., 2008). Likewise, we also detected a substantial increase in the AOX protein levels after the inhibition of mitochondrial complex I by rotenone in both control roots and roots treated with $\mathrm{Cd}$ (Fig. 3). This robust activation of AOX may contribute to the alleviating effect of rotenone on the extensive cell death in barley root tips observed during severe $\mathrm{Cd}$ stress due to the considerable reduction of Cd-induced generation of superoxide at complex III (Tamás et al., 2016).

Involvement of MYB TF in the early response of roots to Cd has been previously described in soybean seedlings, where the level of MYBZ2 expression was increased within $3 \mathrm{~h}$ after $\mathrm{Cd}$ treatment (Chmielowska-Bak et al., 2013). In barley root tips, the MYB1 mRNA transcripts were increased in Cdtreated roots already within $1 \mathrm{~h}$ after the transient $10 \mu \mathrm{M} \mathrm{Cd}$ treatment, and further increased slightly with time and with rising Cd concentrations (Fig. 4). On the one hand, these TFs are part of the mechanism that regulates $\mathrm{Cd}$ uptake and transport, leading to increased Cd accumulation (Zhang et al., 2019; Zhu et al., 2020). But on the other hand, overexpression of the Cd-induced MYB genes resulted in a markedly increased Cd tolerance, while loss of function mutant lines showed enhanced sensitivity to Cd (Agarwal et al., 2020; Zhu et al., 2020). This very early activation of MYB1 expression indicates the key role of MYB1 during Cd stress response in barley roots as a regulator of early gene expression. Furthermore, transgenic barley lines that overexpress the HvMYB1 gene were more tolerant to osmotic and drought stress, compared to the wild type, probably due to the constitutively high level of DHN, GPX and APX gene expression (Alexander et al., 2019). Similarly to barley transgenic lines, in Arabidopsis MYB overexpression lines, the enhanced $\mathrm{Cd}$ tolerance is associated both with enhanced protection against oxidative stress and with increased expression of genes encoding phytochelatin synthase and metallothioneins involved in Cd detoxification of plants (Agarwal et al., 2020). While the expression of MYB1 was markedly increased by IAA treatment of roots, AA application did not influence its expression (Fig. 5). In turn, both PPBo and rotenone slightly attenuated its elevated expression in the Cd-treated roots (Fig. 6). The expression of MdSIMYB1 was upregulated by IAA in apple, while in transgenic tobacco, the overexpression of this gene increased the tolerance of seedlings to salt, drought and cold stresses owing to the induction of stress-responsive genes expression (Wang et al., 2014). In addition, MYB genes have been characterized as an important component of auxin signaling in the regulation of lateral root induction in Arabidopsis seedlings (Shin et al., 2007). These and our results indicate that MYB TFs have a crucial role in the activation of root morphogenic and defense responses to stresses mediated by IAA signaling. 
The level of AOC mRNA was increased in roots treated with $10 \mu \mathrm{M} \mathrm{Cd}$, causing mild stress, already $1 \mathrm{~h}$ after the transient $\mathrm{Cd}$ treatment, and a slight increase was present $2 \mathrm{~h}$ after moderate, $30 \mu \mathrm{M}$ Cd-induced stress (Fig. 4). In both 10 and $30 \mu \mathrm{M}$ Cd-treated roots, a considerable increase of AOC transcript abundance was detected $3 \mathrm{~h}$ after transient treatment. In contrast, severe stress, induced by $60 \mu \mathrm{M} \mathrm{Cd}$ treatment, did not activate $A O C$ expression. This pattern of changes in $A O C$ expression is very similar to the changes detected in IAA level in barley root tip treated with the same concentrations of $\mathrm{Cd}$ (Demecsová et al., 2020). Moreover, exogenously applied IAA activated the expression of the AOC gene, whereas AA did not affect its expression (Fig. 5). While PPBo markedly inhibited the expression of AOC in control as well as in Cd-treated roots, rotenone had only a minor inhibitory effect on Cd-induced AOC expression (Fig. 6). These results imply that IAA signaling is involved, through the induction of AOC expression, in the activation of JA synthesis and accumulation during mild and moderate Cd stresses in barley root tips. Similarly to our result, JA synthesis genes expression was considerably increased within $1 \mathrm{~h}$ of Cd treatment, eventuating in an elevated JA level in the Arabidopsis root (Lei et al., 2020). In Arabidopsis, JA biosynthesis genes were upregulated by IAA, and this induction was strongly impaired in the auxin-signaling mutant (Tiryaki and Staswick, 2002). In addition, JA interacts with auxin, affecting its homeostasis and root system remodeling during the response of seedlings to metal excess (Ronzan et al., 2019). In accordance with these results, tomato JA-deficient mutant showed enhanced sensitivity to $\mathrm{Cd}$ due to the decreased antioxidant enzymes activity resulting in increased ROS formation (Zhao et al., 2016). By contrast, AOC overexpressing Arabidopsis seedlings exhibited increased copper tolerance (Wang et al., 2015), supporting the function of JA in defense mechanisms of plants against excess metal-mediated toxicity.

Similarly to Cd-induced changes in AOC expression, increased NOXB1 expression was a characteristic feature of root tips during mild and with lower intensity during moderated Cd stresses (Fig. 4). The expression of NOXB1 was strongly activated within $1 \mathrm{~h}$ and further increased 2 and $3 \mathrm{~h}$ after the transient treatment with $10 \mu \mathrm{M} C d$. The induction of NOXB1 expression in barley root tip mainly under mild Cd stress further support the idea that NOX is involved in different defense responses but not in an uncontrolled generation of toxic superoxide (Jakubowska et al., 2015; Tamás et al., 2016). The role of NOX in auxin signaling pathway has previously been suggested in root development (Müller et al., 2012). Authors observed that knock-down NOX expression lines exhibited a strong seedling root phenotype resembling phenotypes of mutant lines defective in auxin-regulated processes. In agreement with these results, in our experiments exogenous application of IAA evoked an increase of NOXB1 mRNA levels, whereas AA inhibited its expression in a dose-dependent manner (Fig. 5). Rotenone did not influence the elevated NOXB1 expression in roots exposed to 10 or $30 \mu \mathrm{M}$ Cd (Fig. 6). In turn, PPBo reduced the level of NOXB1 transcripts in both control and Cd-treated roots, suggesting that NOXB1 expression is affected by the depletion of IAA, and an elevated IAA level is required for the activation of NOXB1 in Cd stressed roots to develop appropriate defense responses. In turn, high Cd or AA concentrations- generated ROS probably take part in the attenuation of auxin signaling through the oxidation of IAA, leading to an inactive oxiIAA molecule (Peer et al., 2013). 
On the contrary, early changes in the DHN6 transcripts level, within an hour following the transient Cd treatment, were found in the moderately and severely stressed tips of barley roots (Fig. 4). This strong increase of DHN6 transcripts $1 \mathrm{~h}$ after $60 \mu \mathrm{M}$ Cd treatment remained elevated even up to $3 \mathrm{~h}$ after the severe stress- inducing treatment. The changes induced by $30 \mu \mathrm{M} \mathrm{Cd}$ were similar to those described for $60 \mu \mathrm{M} \mathrm{Cd}$ treatment but with a lower intensity $1 \mathrm{~h}$ after the treatment. When a lower $\mathrm{Cd}(10 \mu \mathrm{M})$ concentration was used, the DHN6 expression activation was detected only 2 and $3 \mathrm{~h}$ after the treatments. These results indicate that the endogenous IAA is not a major signal for the induction of DHN6 expression throughout the Cd stress, because as a previous study has shown $1 \mathrm{~h}$ after the exposure of roots to $\mathrm{Cd}$, the IAA accumulated only in root tips exposed to mild Cd stress, whereas severely stressed roots had a depleted level of IAA (Demecsová et al., 2020). In spite of this fact, exogenous IAA induced DHN6 expression; however, this effect decreased with increasing IAA concentrations (Fig. 5). AA at 10 and $20 \mu \mathrm{M}$ concentrations strongly downregulated its expression $3 \mathrm{~h}$ after the transient treatment (Fig. 5). While PPBo reduced the Cd-induced activation of DHN6 expression only at the lower $10 \mu \mathrm{M} \mathrm{Cd}$ concentration, evoking mild $\mathrm{Cd}$ stress, rotenone inhibited the activation of its expression during all analyzed Cd concentrations (Fig. 6). In barley, several abiotic stress-responsive elements were observed in the promoter region of DHNs, including MYC and MYB TFs binding sites, dehydration-responsive element and abscisic acid-responsive elements (Abedini et al., 2017). Therefore, the expression of several DHNs is activated under various stresses; however, heavy metals specifically activate some of them and probably have a key role during metal detoxification as well as during the reduction of metal-induced damages in cells (Zhang et al., 2006). It has been observed in wheat seedlings that DHN accumulation constitutes a key component in the protection against Cd toxicity induced by salicylic acid (Shakirova et al., 2016). A crucial function of DHNs was observed in metal hyperaccumulator species as well (Xu et al., 2008). Inhibition of expression of the gene encoding DHN in antisense Brassica juncea seedlings led to the increased sensitivity to heavy metal stress besides the reduced accumulation of $\mathrm{Cd}$ in comparison with wild type seedlings. In turn, transgenic tobacco seedlings overexpressing this gene were more tolerant to $\mathrm{Cd}$ or $\mathrm{Zn}$ than control seedlings.

Expression of both APX1 and GPX1 was upregulated in the root tips of Cd-treated roots in a Cd dosedependent manner, and it increased with incubation time after the transient treatment (Fig. 4). While GPX was activated as soon as $1 \mathrm{~h}$ after the transient, mild stress-evoking, $10 \mu \mathrm{M} C \mathrm{~d}$ treatment, APX expression was induced only with severe stress-causing $60 \mu \mathrm{M}$ Cd treatment. This early, mild Cd stress-activated GPX expression accompanied by IAA accumulation indicates the IAA involvement in the signaling process leading to this increased GPX expression in the barley roots. Indeed, while PPBo did not influence the increased APX1 expression either under mild or severe $\mathrm{Cd}$ stress, its application reduced the elevated expression of GPX1 under mild Cd stress. In turn, rotenone had only a slight effect on the Cd-induced GPX1 expression, whereas markedly attenuated Cd-induced APX1 expression (Fig. 6), suggesting that in the induction of APX expression, a crucial role is played by ROS. In agreement with these results, it has previously been reported that $\mathrm{H}_{2} \mathrm{O}_{2}$ level within cells has a key role in the activation of APX expression (Morita et al., 1999). Additionally, both IAA and AA caused an increase in APX1 and GPX1 mRNA levels in the root apices (Fig. 5). However, it is a well-known fact that exogenously applied IAA, at concentrations 
evoking RGI, induces a considerable ROS formation in the tips of plant roots (Ivanchenko et al. 2013), which leads to an increased expression of several antioxidant enzymes, including APX and GPX. Both the transgenic Arabidopsis line with increased endogenous IAA level and wild type plants had increased activity of several antioxidant enzymes during drought stress after IAA application; due to the positive IAA effect on ROS homeostasis (Shi et al., 2014).

The expression of C-Prot was activated to a similar extent in both mildly and severely Cd-stressed roots within $1 \mathrm{~h}$ after the transient treatment and increased further with incubation time (Fig. 4). Both IAA and AA activated the expression of C-Prot in a dose dependent manner; however, AA activated its expression more intensively in comparison with IAA (Fig. 5). In mildly and moderately stressed roots, both PPBo and rotenone reduced the Cd-induced increased expression of C-Prot (Fig. 6), suggesting that both increased IAA and ROS levels upregulated the expression of C-Prot in barley root tips. In salt and Cd tolerant strain (W80) of Chlamydomonas, isolated from seawater, C-Prot activity was markedly increased both under oxidative and Cd stress (Usui et al., 2007). The significance of the rapid recycling of unamendable proteins is further supported by the findings that the C-Prot gene was upregulated during the early stage of stress responses to low- or high- temperature conditions and drought (Stroeher et al., 1997).

The Cd-evoked accumulation of BAXI-1 mRNA was characteristic for moderately and severely stressed roots (Fig. 4). While mild Cd stress caused only a slight activation of BAXI-1, moderate and severe Cd stress strongly activated its expression within $1 \mathrm{~h}$ after the transient treatment of roots with $\mathrm{Cd}$. The abundance of BAXI-1 mRNA was considerably increased by both IAA and AA treatment in the root tips (Fig. 5). Whereas PPBo did not affect its expression, rotenone markedly reduced the $\mathrm{Cd}$-induced expression of BAXI-1 (Fig. 6). Using yeast-based CDNA survival screening technique, numerous Cdtolerant genes have been identified, including BAXI-1 (Wang et al., 2020b). It has been reported that BAXI1 plays a crucial role also in the tolerance mechanisms to lead (Kobylińska and Posmyk, 2016). Authors in this study observed that melatonin had a protective effect against lead toxicity in tobacco suspension cells which was attributed not only to its own antioxidative properties but also to the marked induction of Baxl-1 gene leading to the considerable restriction of cell death. In addition to increased expression of Baxl-1 during several stress conditions, Baxl-1-overexpressing transgenic tobacco seedlings showed markedly increased tolerance to high temperature, salt and water stresses (Isbat et al., 2009). In rice suspension cells, BAXI-1 overexpression did not influence the menadione-induced oxidative stress but markedly altered the metabolic components of several defense pathways against oxidative stress (Ishikawa et al., 2010). Possibly, Baxl-1 suppresses the spreading of cell death in the early stage of stresses to enable the activation of defense and repair mechanisms inevitable for the survival of cells during unfavorable conditions.

\section{Conclusion}

According to these results, we can conclude that even a short, $30 \mathrm{~min}, \mathrm{Cd}$ treatment of roots induced a considerable alteration in gene expression in the barley root tips within an hour after the treatments. The very early activation of MYB1 expression during both mild and severe Cd stresses implies a key role for 
MYB1 during Cd stress in the management of early gene expression response, which is partially regulated by auxin signaling in mildly stressed seedlings. An increase in AOC and NOXB1 expression was a distinguishing feature of root tips response to mild Cd stress and with lower intensity also during moderate $\mathrm{Cd}$ stress. Their expression is activated via IAA signaling and the appropriate root responses to Cd stress is likely regulated by the elevated levels of JA and ROS as a result of elevated expression of AOC and NOXB1, respectively. Meanwhile, early changes in the level of DHN6 transcripts were detected in moderately and severely stressed root tips, and their induction is related to altered ROS homeostasis in cells. Expression of both APX1 and GPX1 was upregulated in the root tips of Cd-treated roots in a dosedependent manner, and it increased with incubation time after the transient treatment. The early activation of GPX expression by mild Cd stress indicates the involvement of IAA in the signaling process. In contrast, early APX expression was induced only with Cd treatment causing severe stress and ROS play central roles in its induction. The expression of C-Prot was activated similarly in both mildly and severely Cd-stressed roots; consequently, both increased IAA and ROS levels take part in the regulation of C-Prot expression in the root tips of barley. The Cd-evoked accumulation of BAXI-1 mRNA was characteristic for moderately and severely stressed roots. Whereas decreased IAA level did not affect its expression, rotenone-mediated ROS depletion markedly reduced the Cd-induced expression of BAXI-1. An early increase of AOX levels in the root tip cells indicated that the reduction of mitochondrial superoxide generation is an important component of barley root response to severe Cd stress.

\section{Declarations}

\section{Conflict of interest statement}

The authors declare that the research was conducted in the absence of any commercial or financial relationships that could be construed as a potential conflict of interest.

\section{Acknowledgements}

This work was supported by the Grant Agency VEGA, project No. 2/0039/20. The authors would also like to thank the anonymous reviewers for their helpful criticisms, who improved the manuscript.

\section{References}

1. Abedini R, GhaneGolmohammadi F, PishkamRad R, Pourabed E, Jafarnezhad A, Shobbar Z-S, Shahbazi M (2017) Plant dehydrins:shedding light on structure and expression patterns of dehydrin gene family in barley. J Plant Res 130:747-763.

2. Agarwal P, Mitra M, Banerjee S, Roy S (2020) MYB4 transcription factor, a member of R2R3subfamily of MYB domain protein, regulates cadmium tolerance via enhanced protection against oxidative damage and increases expression of PCS1 and MT1C in Arabidopsis. Plant Sci 297:110501. 
3. Alexander RD, Wendelboe-Nelson C, Morris PC (2019) The barley transcription factor HvMYB1 is a positive regulator of drought tolerance. Plant Physiol Biochem 142:246-253.

\section{Anjum NA, Ahmad I, Mohmood I, Pacheco M, Duarte AC, Pereira E, Umar S, Ahmad A, Khan NA, Iqbal M, Prasad MNV (2012) Modulation of glutathione and its related enzymes in plants' responses to toxic metals and metalloids - A review. Environ Exp Bot 75:307-324.}

5. Anjum NA, Gill SS, Gill R, Hasanuzzaman M, Duarte AC, Pereira E, Ahmad I, Tuteja R, Tuteja N (2014) Metal/metalloid stress tolerance in plants: role of ascorbate, its redox couple, and associated enzymes. Protoplasma 251:1265-1283.

6. Bochicchio R, Sofo A, Terzano R, Gattullo CE, Amato M, Scopa A (2015) Root architecture and morphometric analysis of Arabidopsis thaliana grown in $\mathrm{Cd} / \mathrm{Cu} / \mathrm{Zn}$-gradient agar dishes: A new screening technique for studying plant response to metals. Plant Physiol Biochem 91:20-27.

7. Bradford MM (1976) A rapid and sensitive method for the quantitation of microgram quantities of protein utilizing the principle of protein-dye binding. Anal Biochem 72:248-254.

8. Castro-Guerrero NA, Rodríguez-Zavala JS, Marín-Hernández A, Rodríguez-Enríquez S, MorenoSánchez R (2008) Enhanced alternative oxidase and antioxidant enzymes under $\mathrm{Cd}^{2+}$ stress in Euglena. J Bioenerg Biomembr 40:227-235.

9. Chen X, Jiang W, Tong T, Chen G, Zeng F, Jang S, Gao W, Li Z, Mak M, Deng F, Chen Z-H (2021) Molecular interaction and evolution of jasmonate signaling with transport and detoxification of heavy metals and metalloids in plants. Front Plant Sci 12:665842.

10. Clemens S (2019) Safer food through plant science: reducing toxic element accumulation in crops. J Exp Bot 70:5537-5557.

11. Chmielowska-Bąk J, Lefèvre I, Lutts S, Deckert J (2013) Short term signaling responses in roots of young soybean seedlings exposed to cadmium stress. J Plant Physiol 170:1585-1594.

12. Demecsová L, Zelinová V, Liptáková L', Tamás L (2020) Mild cadmium stress induces auxin synthesis and accumulation, while severe cadmium stress causes its rapid depletion in barley root tip. Environ Exp Bot 175:104038.

13. Depaepe T, Hendrix S, Janse van Rensburg HC, Van den Ende W, Cuypers A, Van der Straeten D (2021) At the crossroads of survival and death: The reactive oxygen species-ethylene-sugar triad and unfolded protein response. Trends Plant Sci 26:338-351.

14. Gallego SM, Pena LB, Barcia RA, Azpilicueta CE, lannone MF, Rosales EP, Zawoznik MS, Groppa MD, Benavides MP (2012) Unravelling cadmium toxicity and tolerance in plants: Insight into regulatory mechanisms. Environ Exp Bot 83:33-46.

15. Garmier M, Carroll AJ, Delannoy E, Vallet C, Day DA, Small ID, Millar AH (2008) Complex I dysfunction redirects cellular and mitochondrial metabolism in Arabidopsis. Plant Physiol 148:1324-1341.

16. Grudkowska M, Barbara Zagdańska B (2004) Multifunctional role of plant cysteine proteinases. Acta Biochim Pol 51:609-624. 
17. Han M, Wang B, Song G, Shi S (2020) Comparative study of alleviation effects of DMTU and PCIB on root growth inhibition in two tall fescue varieties under cadmium stress. Ecotoxicol Environ Saf 196:110528.

18. Hara M, Kondo M, Kato T (2013) A KS-type dehydrin and its related domains reduce Cu-promoted radical generation and the histidine residues contribute to the radical-reducing activities. J Exp Bot 64:1615-1624.

19. Hu YF, Zhou G, Na XF, Yang L, Nan WB, Liu X, Zhang YQ, Li JL, Bi YR (2013) Cadmium interferes with maintenance of auxin homeostasis in Arabidopsis seedlings. J Plant Physiol 170:965- 975.

20. Isbat M, Zeba N, Kim SR, Hong CB (2009) A BAX inhibitor-1 gene in Capsicum annuum is induced under various abiotic stresses and endows multi-tolerance in transgenic tobacco. J Plant Physiol 166:1685-1693.

21. Ishikawa T, Takahara K, Hirabayashi T, Matsumura H, Fujisawa S, Terauchi R, Uchimiya H, KawaiYamada M (2010) Metabolome analysis of response to oxidative stress in rice suspension cells overexpressing cell death suppressor Bax inhibitor-1. Plant Cell Physiol 51:9-20.

22. Ishikawa T, Watanabe N, Nagano M, Kawai-Yamada M, Lam E (2011) Bax inhibitor-1: a highly conserved endoplasmic reticulum-resident cell death suppressor. Cell Death Differ 18:1271-1278.

23. Ivanova A, Law SR, Narsai R, Duncan O, Lee J-H, Zhang B, Van Aken O, Radomiljac JD, van der Merwe $\mathrm{M}$, Yi K, Whelan J (2014) A functional antagonistic relationship between auxin and mitochondrial retrograde signaling regulates alternative oxidase1a expression in Arabidopsis. Plant Physiol 165:1233-1254.

24. Ivanchenko MG, den Os D, Monshausen GB, Dubrovsky JG, Bednářová A, Krishnan N (2013) Auxin increases the hydrogen peroxide $\left(\mathrm{H}_{2} \mathrm{O}_{2}\right)$ concentration in tomato (Solanum lycopersicum) root tips while inhibiting root growth. Ann Bot 112:1107-1116.

25. Jakubowska D, Janicka-Russak, M, Kabała K, Migocka M, Reda M (2015) Modification of plasma membrane NADPH oxidase activity in cucumber seedling roots in response to cadmium stress. Plant Sci. 234:50-59

26. Kapoor D, Singh S, Kumar V, Romero R, Prasad R, Singh J (2019) Antioxidant enzymes regulation in plants in reference to reactive oxygen species (ROS) and reactive nitrogen species (RNS). Plant Gene 19:100182.

27. Kazan K (2013) Auxin and the integration of environmental signals into plant root development. Ann Bot 112:1655-1665.

28. Keunen E, Remans T, Bohler S, Vangronsveld J, Cuypers A (2011) Metal-induced oxidative stress and plant mitochondria. Int J Mol Sci 12:6894-6918.

29. Kerchev PI, De Clercq I, Denecker J, Mühlenbock P, Kumpf R, Nguyen L, Audenaert D, Dejonghe W, Van Breusegem $F$ (2014) Mitochondrial perturbation negatively affects auxin signaling. Mol Plant 7:11381150.

30. Kobylińska A, Posmyk MM (2016) Melatonin restricts Pb-induced PCD by enhancing BI-1 expression in tobacco suspension cells. Biometals 29:1059-1074. 
31. Lei GJ, Sun L, Sun Y, Zhu XF, Li GX, Zheng SJ (2020) Jasmonic acid alleviates cadmium toxicity in Arabidopsis via suppression of cadmium uptake and translocation. J Integr Plant Biol 62:218-227.

32. Li C, Ng CK-Y, Fan L-M (2015) MYB transcription factors, active players in abiotic stress signaling. Environ Exp Bot 114:80-91.

33. Maxwell DP, Wang Y, Mclntosh L (1999) The alternative oxidase lowers mitochondrial reactive oxygen production in plant cells. Proc Natl Acad Sci USA 96:8271-8276.

34. Morita S, Kaminaka H, Masumura T, Tanaka K (1999) Induction of rice cytosolic ascorbate peroxidase mRNA by oxidative stress; the involvement of hydrogen peroxide in oxidative stress signalling. Plant Cell Physiol 40:417-422.

35. Müller K, Linkies A, Leubner-Metzger G, Kermode AR (2012) Role of a respiratory burst oxidase of Lepidium sativum (cress) seedlings in root development and auxin signalling. J Exp Bot 63:63256334.

36. Palma JM, Sandalio LM, Corpas FJ, Romero-Puertas MC, McCarthy I, del Río LA (2002) Plant proteases, protein degradation, and oxidative stress: role of peroxisomes. Plant Physiol Biochem 40:521-530.

37. Pan J, Plant JA, Voulvoulis N, Oates CJ, Ihlenfeld C (2010) Cadmium levels in Europe: implications for human health. Environ Geochem Health 32:1-12.

38. Peer WA, Cheng Y, Murphy AS (2013) Evidence of oxidative attenuation of auxin signalling. J Exp Bot 64:2629-2639.

39. Potters G, Pasternak TP, Guisez Y, Jansen MAK (2009) Different stresses, similar morphogenic responses: integrating a plethora of pathways. Plant Cell Environ 32:158-169.

40. Rascio N, Navari-Izzo F (2011) Heavy metal hyperaccumulating plants: How and why do they do it? And what makes them so interesting? Plant Sci 180:169-181.

41. Romero-Puertas MC, Palma JM, Gómez M, del Río LA, Sandalio LM (2002) Cadmium causes the oxidative modification of proteins in pea plants. Plant Cell Environ 25:677-686.

42. Romero-Puertas MC, Terrón-Camero LC, Peláez-Vico MÁ, Olmedilla A, Sandalio LM (2019) Reactive oxygen and nitrogen species as key indicators of plant responses to Cd stress. Environ Exp Bot 161:107-119.

43. Ronzan M, Piacentini D, Fattorini L, Della Rovere F, Caboni E, Eiche E, Ziegler J, Hause B, Riemann M, Betti C, Altamura MM, Falasca G (2019) Auxin-jasmonate crosstalk in Oryza sativa L. root system formation after cadmium and/or arsenic exposure. Environ Exp Bot 165:59-69.

44. Sanjaya, Hsiao P-Y, Su R-C, Ko S-S, Tong C-G, Yang R-Y, Chan M-T (2008) Overexpression of Arabidopsis thaliana tryptophan synthase beta 1 (AtTSB1) in Arabidopsis and tomato confers tolerance to cadmium stress. Plant Cell Environ 31:1074-1085.

45. Shakirova FM, Allagulova ChR, Maslennikova DR, Klyuchnikova EO, Avalbaev AM, Bezrukova MV (2016) Salicylic acid-induced protection against cadmium toxicity in wheat plants. Environ Exp Bot 122:19-28. 
46. Sharma SS, Dietz K-J (2008) The relationship between metal toxicity and cellular redox imbalance. Trends Plant Sci 14:43-50.

47. Shi H, Chen L, Ye T, Liu X, Ding K, Chan Z (2014) Modulation of auxin content in Arabidopsis confers improved drought stress resistance. Plant Physiol Biochem 82:209-217.

48. Shin R, Burch AY, Huppert KA, Tiwari SB, Murphy AS, Guilfoyle TJ, Schachtman DP (2007) The Arabidopsis transcription factor MYB77 modulates auxin signal transduction. Plant Cell 19:24402453.

49. Stroeher VL, Maclagan JL, Good AG (1997) Molecular cloning of a Brassica napus cysteine protease gene inducible by drought and low temperature stress. Physiol Plant 101:389-397.

50. Sun LR, Zhao ZJ, Hao FS (2019) NADPH oxidases, essential players of hormone signalings in plant development and response to stresses. Plant Signal Behav 14:e1657343.

51. Sun T, Cen G, You,C, Lou W, Wang Z, Su W, Wang W, Li D, Que Y, Su Y (2020) ScAOC1, an allene oxide cyclase gene, confers defense response to biotic and abiotic stresses in sugarcane. Plant Cell Rep 39:1785-1801.

52. Tamás L, Mistrík I, Zelinová V (2016) Cadmium activates both diphenyleneiodonium- and rotenonesensitive superoxide production in barley root tips. Planta 244:1277-1287.

53. Tiryaki I, Staswick PE (2002) An Arabidopsis mutant defective in jasmonate response is allelic to the auxin-signaling mutant axr1. Plant Physiol 130:887-894.

54. Usui M, Tanaka S, Miyasaka H, Suzuki Y, Shioi Y (2007) Characterization of cysteine protease induced by oxidative stress in cells of Chlamydomonas sp. strain W80. Physiol Plant 131:519-526.

55. Vanlerberghe GC (2013) Alternative oxidase: A mitochondrial respiratory pathway to maintain metabolic and signaling homeostasis during abiotic and biotic stress in plants. Int $\mathrm{J}$ Mol Sci 14:6805-6847.

56. Wang M, Zou J, Duan X, Jiang W, Liu D (2007) Cadmium accumulation and its effects on metal uptake in maize (Zea mays L.). Bioresource Technol 98:82-88.

57. Wang R-K, Cao Z-H, Hao Y-J (2014) Overexpression of a R2R3 MYB gene MdSIMYB1 increases tolerance to multiple stresses in transgenic tobacco and apples. Physiol Plant 150:76-87.

58. Wang Y, Liu H, Xin Q (2015) Improvement of copper tolerance of Arabidopsis by transgenic expression of an allene oxide cyclase gene, GhAOC1, in upland cotton (Gossypium hirsutum L.). Crop J 3:343-352.

59. Wang J, Song L, Gong X, Xu J, Li M (2020a) Function of jasmonic acid in plant regulation and response to abiotic stress. Int J Mol Sci 21:1446.

60. Wang B, Zhang M, Zhang J, Huang L, Chen X, Jiang M, Tan M (2020b) Profiling of rice Cd-tolerant genes through yeast-based cDNA library survival screening. Plant Physiol Biochem 155:429-436.

61. Watanabe N, Lam E (2009) Bax Inhibitor-1, a conserved cell death suppressor, is a key molecular switch downstream from a variety of biotic and abiotic stress signals in plants. Int $\mathrm{J}$ Mol Sci 10:3149-3167. 
62. Xu J, Zhang YX, Wei W, Han L, Guan ZQ, Wang Z, Chai TY (2008) BjDHNs confer heavy-metal tolerance in plants. Mol Biotechnol 38:91-98.

63. Yu Z, Wang X, Zhang L (2018) Structural and functional dynamics of dehydrins: A plant protector protein under abiotic stress. Int J Mol Sci 19:3420.

64. Zelinová V, Demecsová L, Tamás L (2019) Impact of antimycin A and myxothiazol on cadmiuminduced superoxide, hydrogen peroxide, and nitric oxide generation in barley root tip. Protoplasma 256:1375-1383.

65. Zhang Y, Li J, Yu F, Cong L, Wang L, Burkard G, Chai T (2006) Cloning and expression analysis of $\mathrm{SK}_{\mathrm{n}}$-type dehydrin gene from bean in response to heavy metals. Mol Biotechnol 32:205-217.

66. Zhang P, Wang R, Ju Q, Li W, Tran L-SP, Xu J (2019) The R2R3-MYB transcription factor MYB49 regulates cadmium accumulation. Plant Physiol 180:529-542.

67. Zhao S, Ma Q, Xu X, Li G, Hao L (2016) Tomato jasmonic acid-deficient mutant spr2 seedling response to cadmium stress. J. Plant Growth Regul 35:603-610.

68. Zhu S, Shi W, Jie Y, Zhou Q, Song C (2020) A MYB transcription factor, BnMYB2, cloned from ramie (Boehmeria nivea) is involved in cadmium tolerance and accumulation. Plos One 15:e0233375.

69. Zulfiqar F, Ashraf M (2021) Bioregulators: unlocking their potential role in regulation of the plant oxidative defense system. Plant Mol Biol 105:11-41.

\section{Figures}

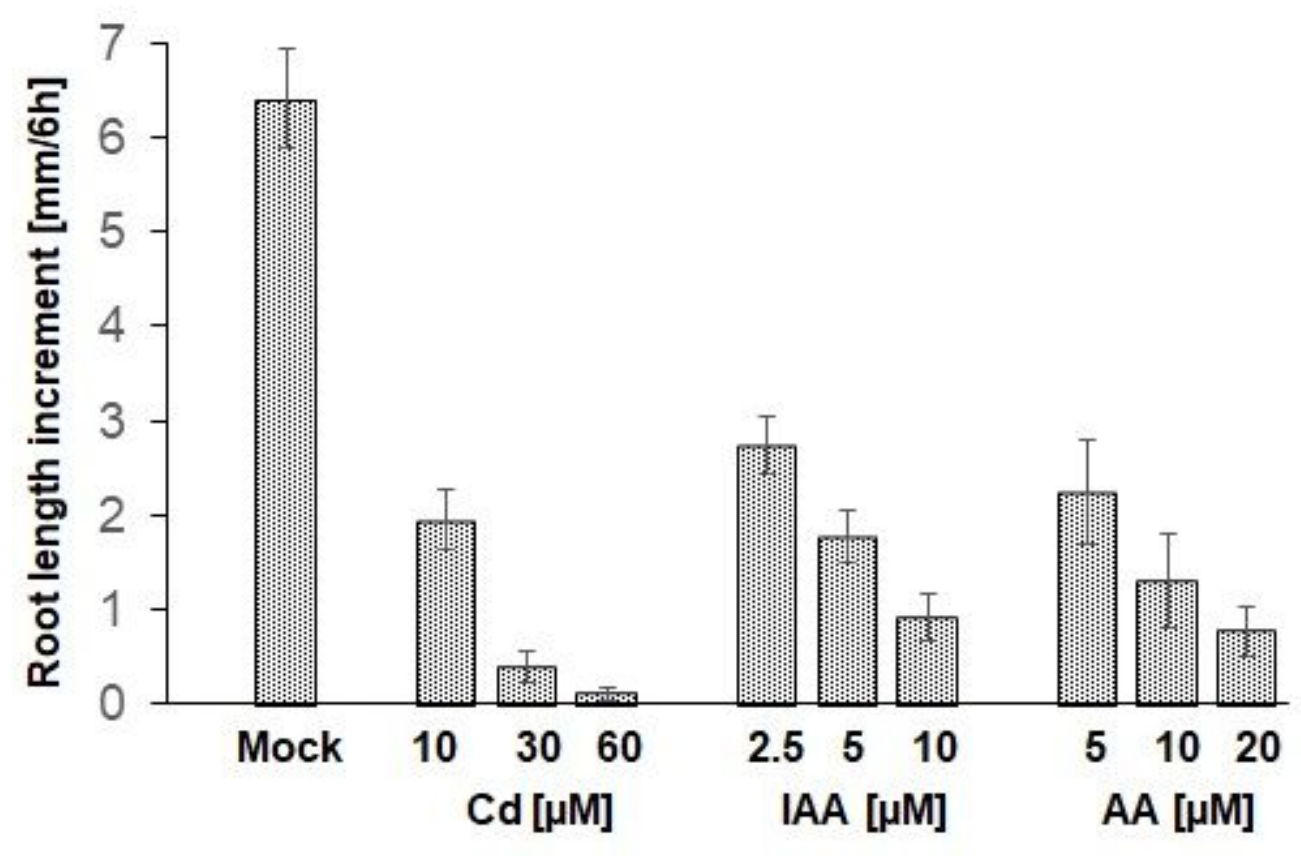

Fig. 1

Figure 1 
Measurement of root length increments $6 \mathrm{~h}$ after the transient $30 \mathrm{~min}$ treatment of roots with distilled water (Mock); or with 10, 30 or $60 \mu \mathrm{M}$ Cd; or with $2.5,5$ or $10 \mu \mathrm{M} \mathrm{IAA}$; or with 5,10 or $20 \mu \mathrm{M} \mathrm{AA}$.

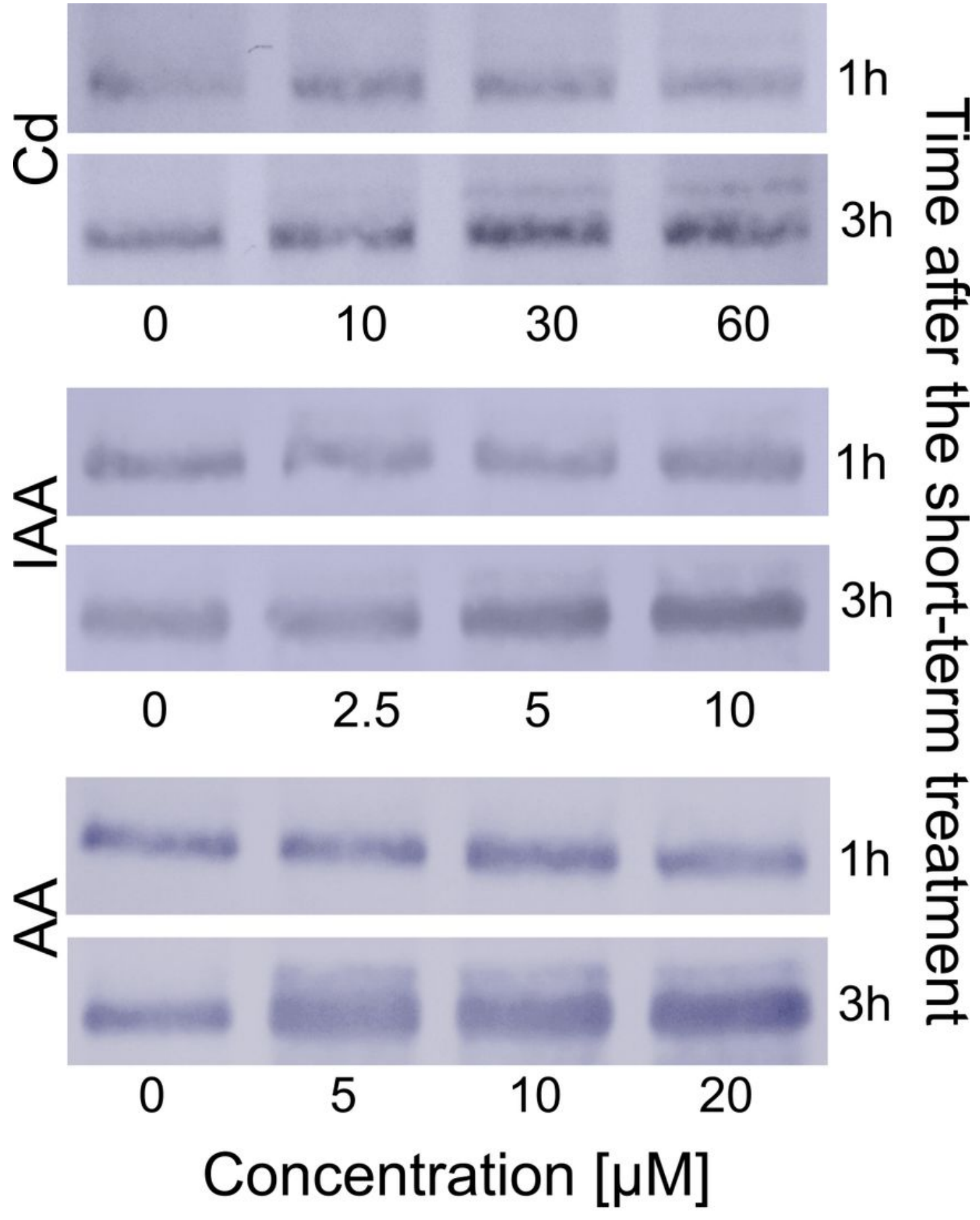

Fig. 2

Figure 2

Western blot analysis of AOX levels 1 and $3 \mathrm{~h}$ after the 30 min transient treatment of roots with $0,10,30$ or $60 \mu \mathrm{M}$ Cd; or with $0,2.5,5$ or $10 \mu \mathrm{M}$ IAA; or with $0,5,10$ or $20 \mu \mathrm{M}$ AA in barley root tips. 


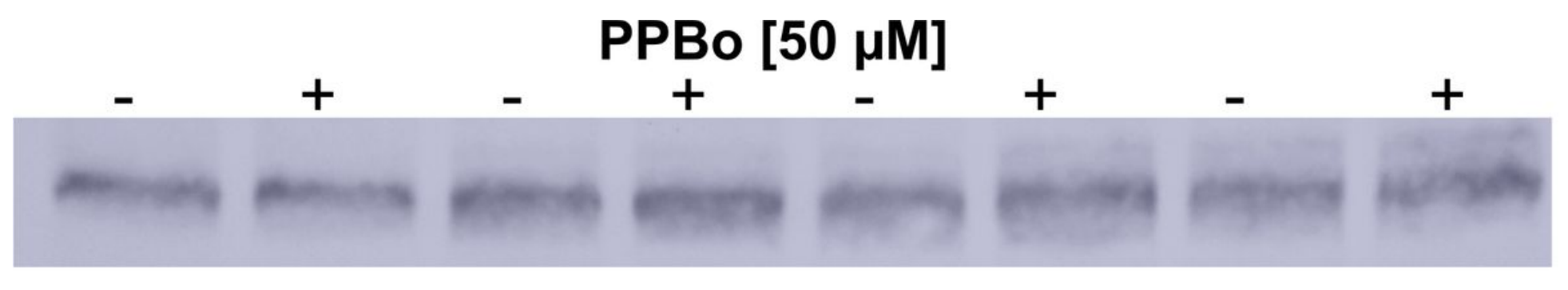

\section{Rotenone $[5 \mu \mathrm{M}]$}

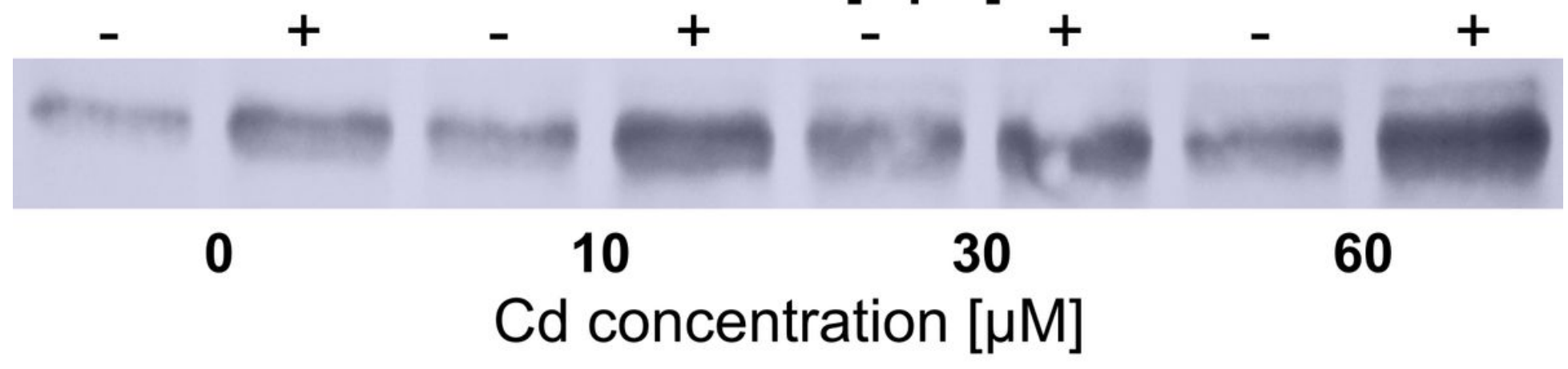

Fig. 3

Figure 3

Western blot analysis of AOX levels in barley root tips $3 \mathrm{~h}$ after the transient treatment of roots for $30 \mathrm{~min}$ with $0,10,30$ or $60 \mu \mathrm{M} \mathrm{Cd}$ and post-treatment with $50 \mu \mathrm{M}$ PPBo or co-treatment with $5 \mu \mathrm{M}$ rotenone. 
Actin

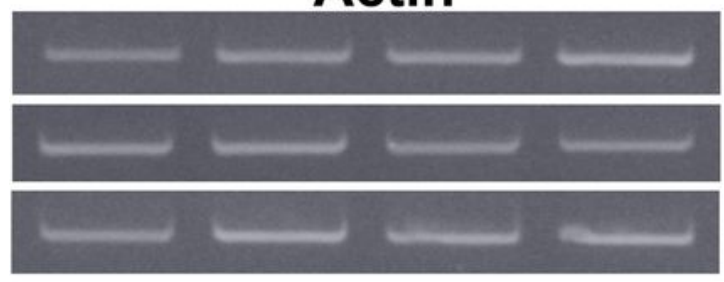

MYB1

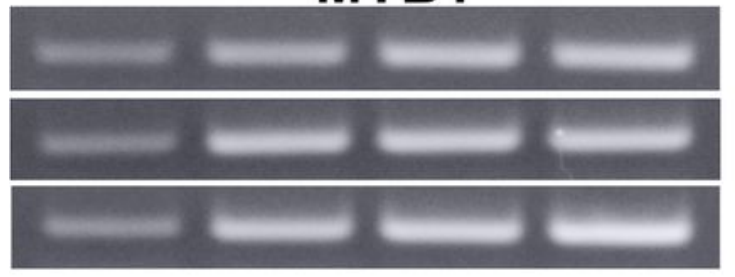

NOXB1

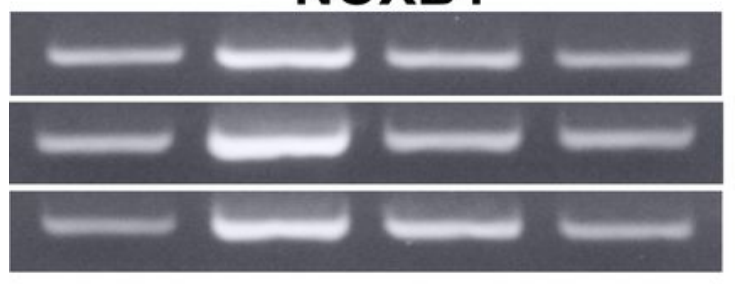

APX1

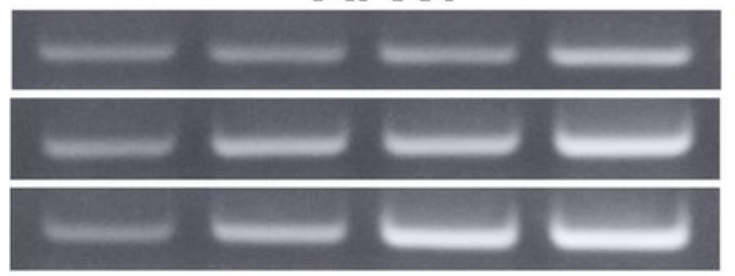

BAXI-1

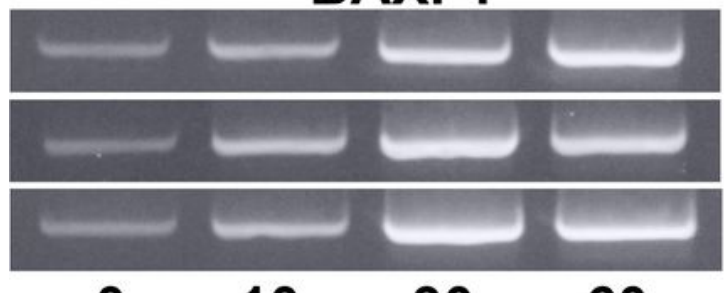

$\begin{array}{llll}0 & 10 & 30 & 60\end{array}$
Ubiquitin

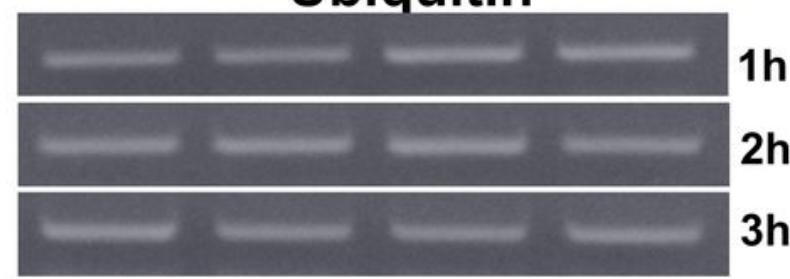

AOC

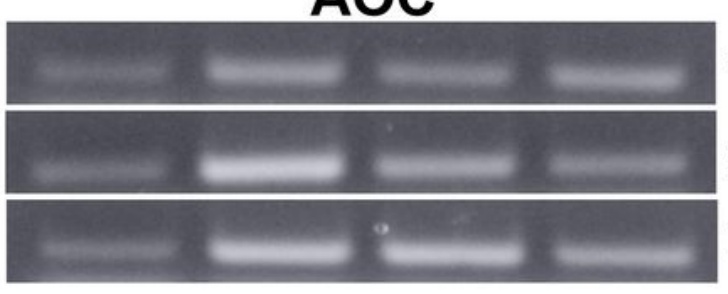

DHN6

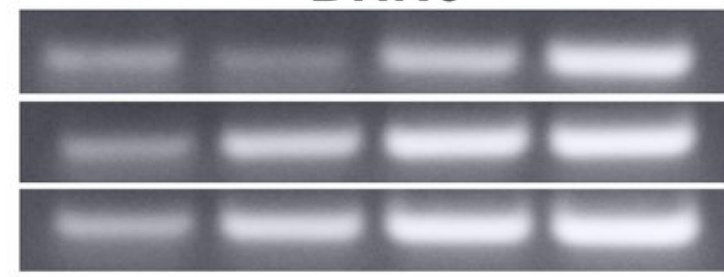

GPX1

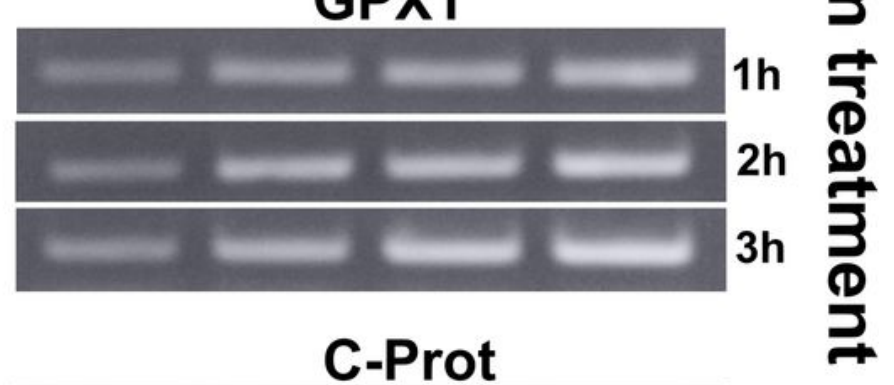

$1 \mathrm{~h}$

$2 \mathrm{~h}$

$3 \mathrm{~h}$

Cd concentration $[\mu \mathrm{M}]$

Fig. 4

Figure 4

Semi-quantitative RT-PCR analysis of gene expression 1, 2 and $3 \mathrm{~h}$ after the 30 min transient treatment of barley roots with $0,10,30$ or $60 \mu \mathrm{M} C d$. 

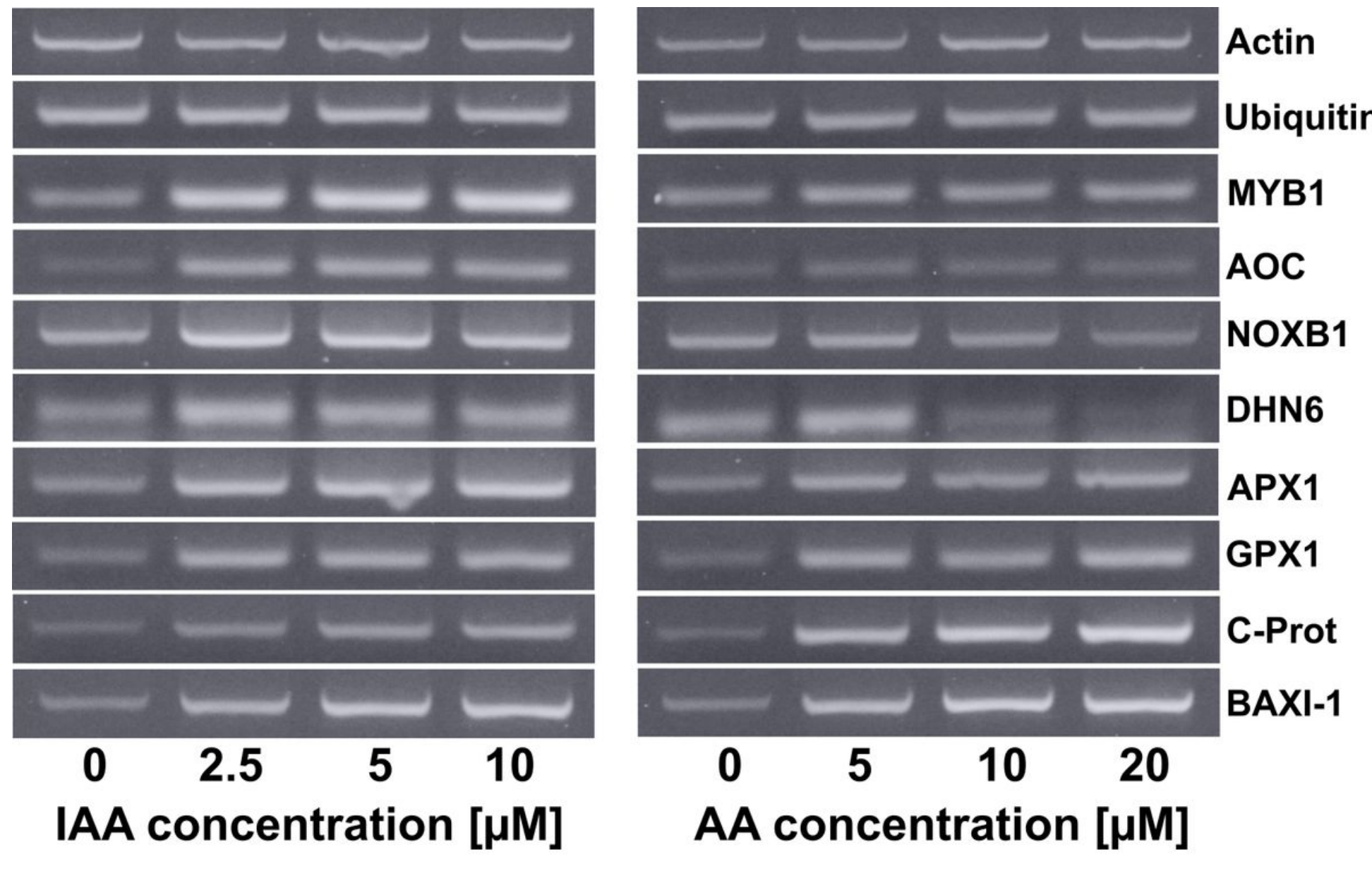

Fig. 5

Figure 5

Semi-quantitative RT-PCR analysis of gene expression in barley root tips $3 \mathrm{~h}$ after the transient treatment of roots for 30 min with $0,2.5,5$ or $10 \mu \mathrm{M}$ IAA; or with $0,5,10$ or $20 \mu \mathrm{M}$ AA. 


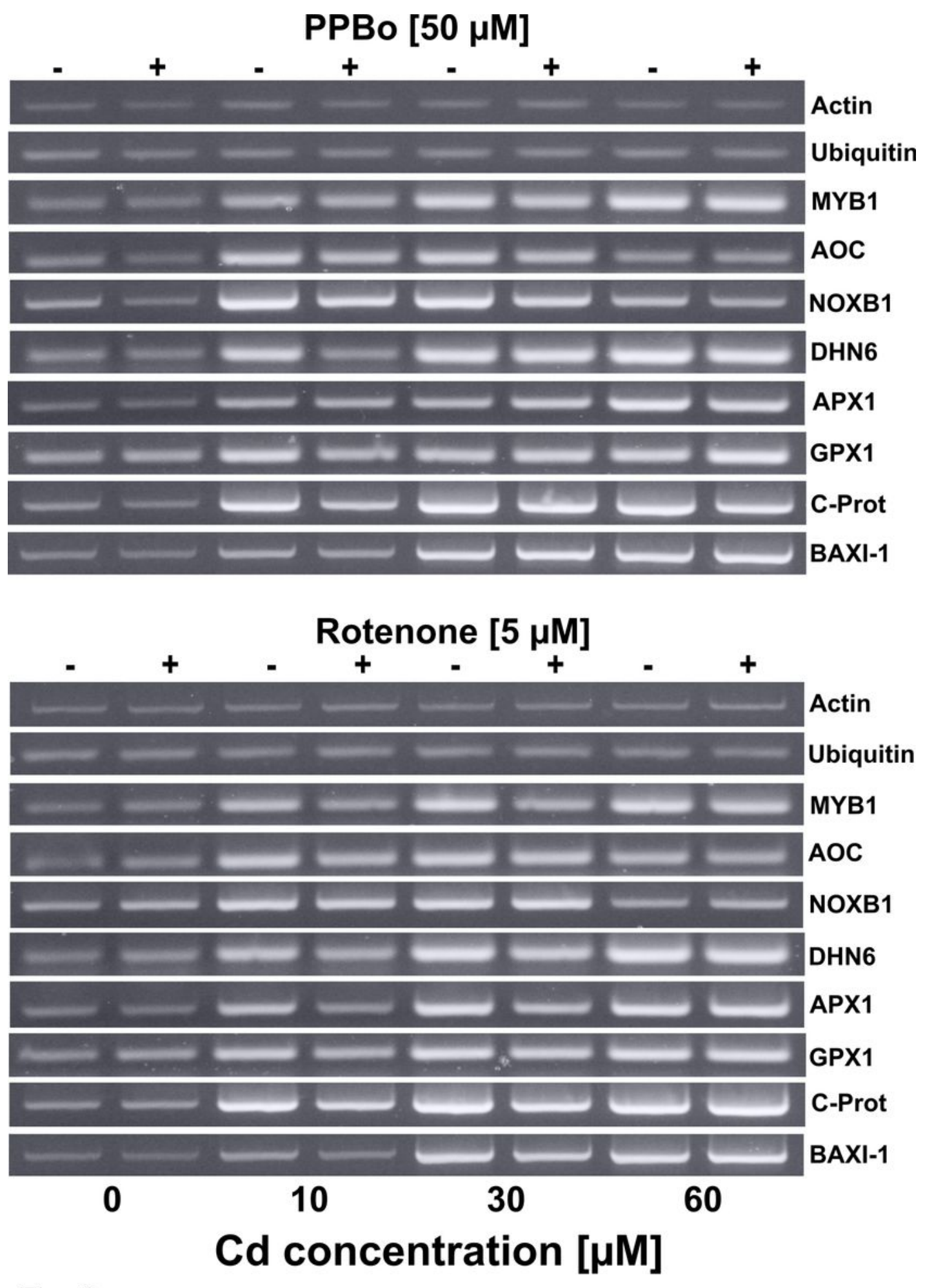

Fig. 6

Figure 6

Semi-quantitative RT-PCR analysis of gene expression in barley root tips $3 \mathrm{~h}$ after the transient treatment of roots for 30 min with $0,10,30$ or $60 \mu \mathrm{M}$ Cd and post-treatment with $50 \mu \mathrm{M}$ PPBo or co-treatment with 5 $\mu \mathrm{M}$ rotenone. 


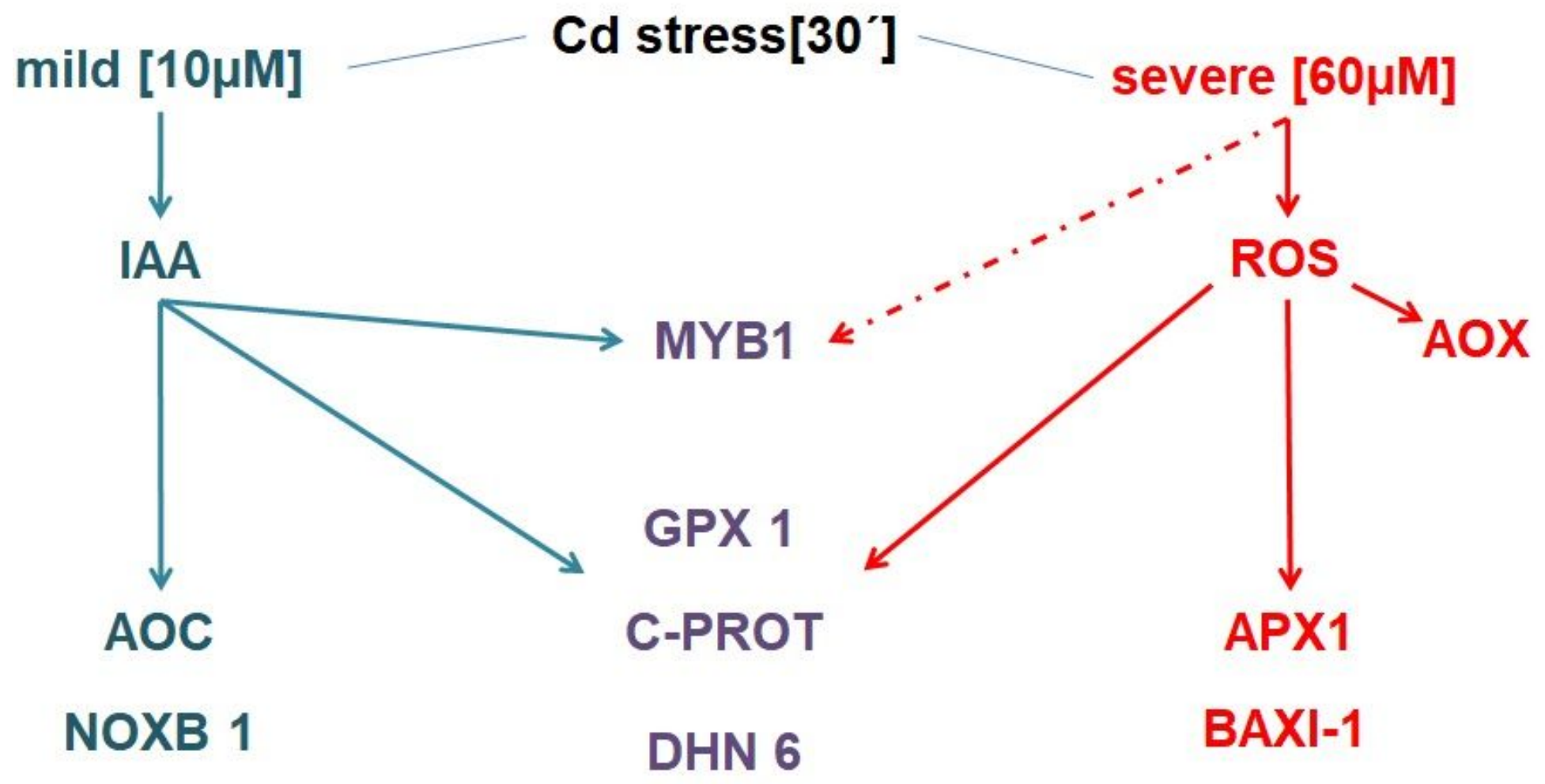

root growth reorientation

root growth inhibition

Fig. 7

Figure 7

Signaling role of IAA and ROS in the Cd-induced early gene expression response in barley root tip.

\section{Supplementary Files}

This is a list of supplementary files associated with this preprint. Click to download.

- Suppl.1.docx 